\section{Every Automobile Its Own Elevator}

By Robert G. Skerrett

NE of America's biggest nate lost motion in evers whase of transportationusing that wing that term in its wilest sense. money to move anything any distance, for the work involves an expenditure of time and effort. Whenever commodities are shifterl from one conveying medium to another there is a break that halts for steady flow of the goods. Trite as these facts are, and Trite as these facts are, and
well known by every traftic well known by every traftic a verage citizen realizes how much more he has to pay in the long run because of the interruptions in the transportational tide.

The automotive vehicle is doing much to bridge the gap between terminal facilities; it is speeding up the transfer of merchandise where formerly the service limped; but the great majority of owners of cars and trucks have not yet awakened to the full potentialities of these vehicles as carriers. In industrial and business circles, for instance, it has occurred to comparatively few that it

is entirely practicable to utilize the hill-climbing pow ers of the truck and car to link directly the floors of shops, factories, warehouses, garages, etc., with the public highways, ancl thus to avoid dependence upon the elevator as an intermediate agency.

Take the general run of department stores, manufacturing establishments, and bustling warehouses, and what is the usual procedure in getting wares, products, and freight broadly in and out of the buildings? Wellnigh invariably, inter-floor movement is effected by means of more or less capacious elerators. These lifts use a platform on the ground level as the link between themselves and the between themselves and the delivery wagons and trucks
that bring in or take away that bring in or take away the various commodities involved. The mind instinchandlings necessary to deal either with outbound or arriving goods.

Vithout any intention to unclerestimate the elevator it should be plain that much might be saved if every story could, in effect, lie just as accessible to the motor vehicle as the ground floor and this without the help of the freight lift. Why not make it practicable for trucks and delivery cars to climb directly to any floor of a busing of a business or industrial establishment, there to load or unload as the case may be? This can be done.

Of course, many of us are familiar with those inclined extensions of the street commonly termed ramps, which make it possible for motor vehicles to get in and out of the basements or to reach one or more of the floors of a structure above the ground level. This means of ingress and egress has been adopted for a goodly number of garages, and has served to obviate the installation of elevators. While a step in the right lirection, these ramps hava

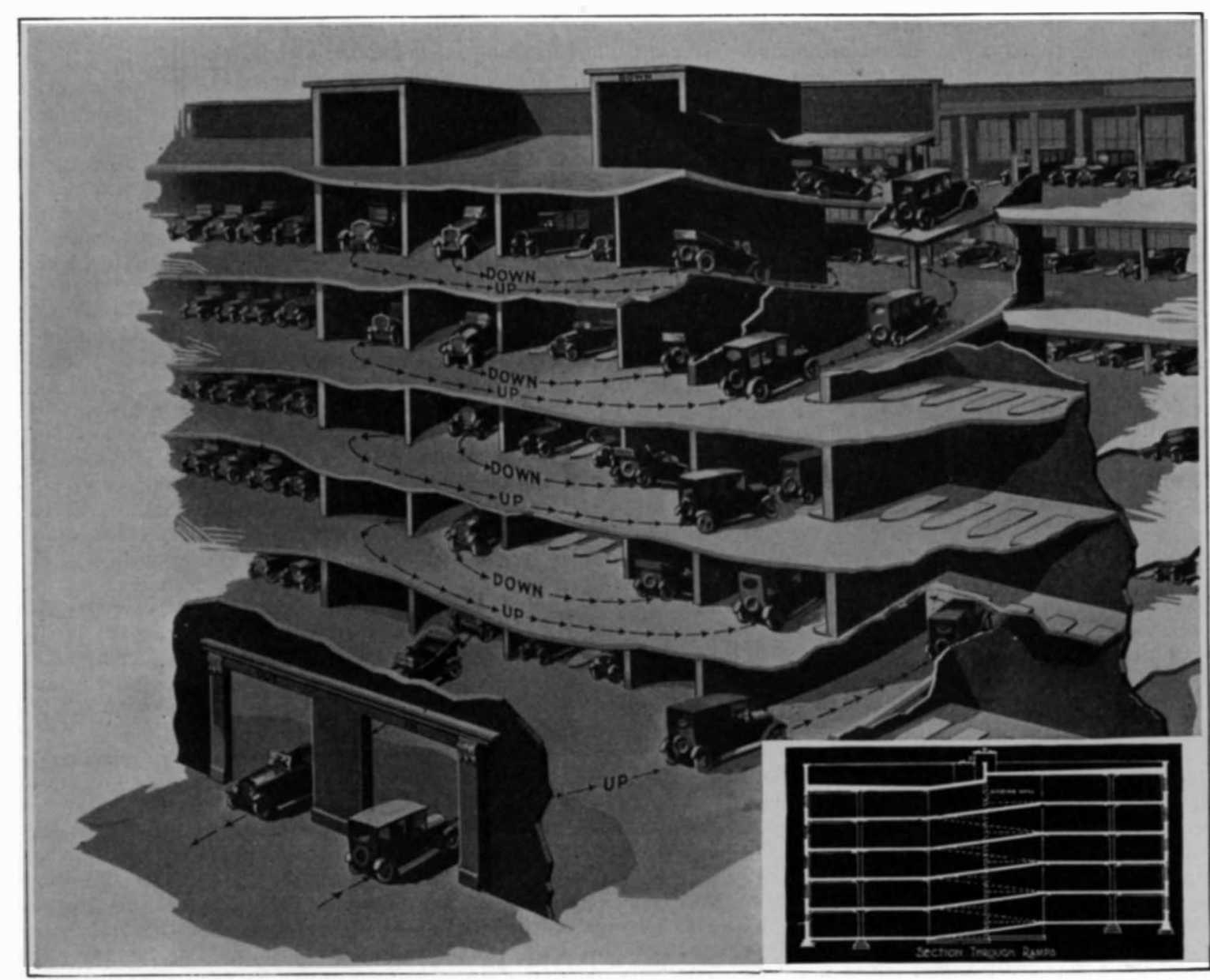

Sectional views of two garages with staggered floors, equipped with a central motor ramp in place of an elevator. The larger seems practical also for heavy inter-floor movements in warehouses, etc.
A Near-Diesel Engine for the Airplane

By Harold F. Blanchard

N OTHING could be more interesting, to those familiar with internal combustion problems, than the news that the Diesel engine has been successfully applied to airplane practice. The new engine has been installed in a German monoplane and was designed by Professor Junkers. The advantages claimed are those of low weight per horsepower, increased reliability, higher fuel economy, greater simplicity, safety against fire, and perfect balance.

In order to appreciate fully the features of this engine it is necessary to explain the Diesel engine principle. In the true Diesel neither carburetor nor ignition is employed. The compression is extremely high. Instead of employing a maximum compression pressure of 80 to 100 pounds as in the ordinary designs with which we are familiar, compressions as high as 600 or 700 pounds are employed. The extreme compression raises the air to a very high temperature so that when a carefully measured quantity of fuel is injected into the cylinder at just the right unker engine of modified Diesel type for airplane use moment the air is so hot that the fuel immediately takes fire. "Throttling" of the engine is obtained by varying the quantity of fuel delivered. The injection of the fuel, by the way, occurs in the instant just before the piston reaches top dead center. The fuel is immediately vaporized by the excessively hot air and is thoroughly distributed throughout the combustion chamber almost instantly. From this consideration of the subject it is plain that the Diesel engine is a type in which the compression pressure is constant whereas in the ordinary type used in airplane work the comaccording to the by opening and closing the throttle.

When Diesel engines. were first produced they attracted considerable attention because of their unusual economy: no type of prime mover has yet been devised that approaches the true Diesel here This economy is due to the fact that a constant compression cycle is more efficient than a variable compression cycle, and also because efficiency increases with the compression pressure which is very much higher in the Diesel than in other types.

The Diesel was long considered out of the question for use in automobiles or airplanes because of its ex treme weight. It was necessary to make the cylinder very heary because of the high pressures generated in it, and the reciprocating parts had to be strong to stand the high acceleration forces developed.

The Junkers Diesel engine is a modification of the true Diesel in that high but not extreme compression pressures are used (about 210 pounds); and because of this reduction in pressure jump-spark ignition is used to ignite the charge. It is a six-cylinder two-cycle, with (Continued on page 79) 


\section{Are You Going After Foreign Trade?}

If so are you sure that your inventions and trade-marks actually belong to you in foreign markets? Unless you avail yourself of the right to acquire foreign patents and trade-mark registrations, you may find that another has preceded you and has actually appropriated your inventions and trademarks and obtained legal ownership thereof, whereby he can bar your goods from foreign markets. Such a proceeding is permissible under the laws of many foreign countries.

Many have lost their markets in certain foreign countries by overlooking this fact.

Many of our clients are preparing to extend their business by seeking patent and trademark protection in foreign countries.

We should be glad to have you avail yourself of our services.

\section{Foreign Patent and Trade-} mark Department

\section{MUNN \& $C O$.}

\section{Woolworth Building New York City}

C MACHINES Corliss Engines, Brewers The VILTER MFG. CO.
999 Clinton Street

We Will Make It

duretl from any metal and finished in any cillur.
Waterbury Button Co., Waterbury, Conn.

Experimental and Model Work

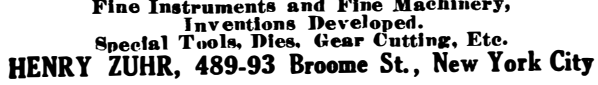

\section{ASBESTOS}

Wuantity Whe produce all grades at ous our wortld famous
BELL ASBESTOS MINES in Canada. We also carry fibres, spin yarns,
Asbestos products.

For anything you want in Asbestos, turn to KEASBEY \& MATTISON COMPANY AMBLER, PENNA., U. S. A.

\section{Every Automobile Its Own} Elevator

(Continued from page 75)

to depend upon elevators to transport a few units at a time-again making up the
train when the desired level is reached. The motor ramp is designed so as to avoid this interruption to speedy transfer and lends itself to the inter-floor travel

these trailer trains in their entirety.

Without further elaboration, it should be self-evident that the d'Humy system is susceptible of meeting a very wide
range of service demands, and may be the range of service demands, and may be the
means of doing away with operations that means of doing away with operations that now occasion much loss of time and the
imposition of heavy charges. Finally, let it be said that the immediate future of the automotive industry is dependent upon the prompt providing of ample garage facilities in our principal cities garage facilities in our principal cities.
Many a prospective car owner is hesitatMany a prospective car owner is hesitat-
ing because he cannot be sure of a coning because he cannot be sure of a con-
venient place in which to house such a vehicle; and it is likewise vital that these accommodations be offered at prices that will be in keeping with the average purse. The motor ramp, as Mr. d'Humy has conceived it, seems to offer the relief so much desired. His solution of a vexed problem is so simple that one wonders why it has not been developed before.

\section{A Near-Diesel Engine for the Airplane \\ (Continued from page 65)}

two pistons per cylinder; it possesses no valves.

shown by the illustration the pistons are opposed head on, there being two separate crankshafts, one for each six pistons. The two crankshafts are con-
nected by gearing at one end of the crankcase. One piston uncovers the intake ports when it nears the bottom of its stroke and the other piston uncovers the exhaust ports. The exhaust ports are larger and are uncovered first. The cycle of events during one complete revolution is as follows, beginning with the piston at top dead center on the compression stroke. A measured quantity of fuel has just been sprayed into the chamber through the nozzle seen in the bottom of
the sectional drawing. This spreads through the highly compressed pure air in through the highly compressed pure air in
the combustion chamber. Just then a the combustion chamber. Just then a
spark occurs and ignites the mixture. The pistons move out simultaneously until the exhaust ports are uncovered by the left piston. A large part of the annular .chamber surrounding these ports. Then as the pistons move a little farther the intake ports are uncovered by the other piston and a charge of pure air surges in, sweeping before it the burned gases and driving them out of the
exhaust ports. By the time that the inexhaust ports. By the time that the in
take ports are covered by the return stroke of the piston all exhaust gas has been driven from the cylinder and nothing but pure air remains. Air is delivered to the intake ports under slight pressure im posed by a blower built into one end of the engine. Continued inward movement of the two pistons compresses the air an when the pistons are close to upper dead center a new charge of fuel is injected,
spark occurs and the cycle is repeated. The weight per horsepower is low pounds) because there are twice as many power strokes as in the ordinary engine. power strokes as in the ordinary engine. because the engine is very much simple than the usual four-cycle type in that it has no valves, although the fuel injection apparatus and the double crankshaft The engine is in perfect balance since the in and out movements of the reciprocating parts in each cylinder absolutely cancel each other. Better fuel econom is obtained because higher pressure is used, exhaust back pressure is eliminated (referring to the pressure on the cause the Diesel cycle is inherently more efficient. It is safer against fire since the air and gasoline are not

Developing One Million Horsepower from Tidal Energy (Continued from page 67)

industrial area of South Wales; thirdly, to the English Midlands, of which Birmngham is the most important center and fourthly, there will be the supply of

the Thames Valley and London, whit
115 miles from the power station.

A lock capable of passing the largest ocean vessels will be built near the center nel into which the turbines discharge Vessels will be towed through this channel by electric towing engines, moving on each wall of the dam, and the lock will
be provided at each gate with a bascule bridge for the passage of railway train and shipping.

The area of the deep-water basin above the dam will be 27 square miles. Along the banks will be built suitable piers, warehouses and storage yards to accommodat the shipping and freight. On the land back of the docks will be erected the various industrial plants, which, as at Niagara, will be drawn to the Severn by the prospects of cheap building sites and shipping facilities.

\section{A Daring Ship Design}

mixture of one part cement to one part of crushed coke, $1 / 2$ inch and smaller, which gave a weight of 110 pounds per cubic foot exclusive of reinforcing, as compared with 150 pounds for ordinary The thickness of shell was greater in these vessels than would ordinarily be used, because of the omission of transcylindrical sections is ten inches thick at the bottom and seven inches at the top. The interior surface of all oil compartments was given two coats of spar varnish, and the outer hull surface painted With a bridge cement.

Tunched sidewars July was successfully to draw almost exactly the calculated amount of water. The second tanker will e ready for launching shortly.

Each vessel is 298 feet long overall, 33 feet 9 inch beam and 21 feet 10 inches "Koka Seki" and Its Uses

"K OKA SEKI" is a variety of pumice reports Vice which, as far as now known, Yokohama, is only found in the small group of Niijima Islands (New Islands), which lie off the coast of the Idzu Peninsula about 90 miles south of Tokyo. Though used in Niijima from ancient times as a building material, only comparatively recently has "Koka Seki" become known commercially in Japan tensile strength, and capability of resisting $1,300^{\circ} \mathrm{C}$. of heat, it is suitable for boiler and furnace construction as well as inner linings of safes and the manufacture of ice chests. As it is claimed, it can be easily cut, will take a surface of paint or metal plating, and as nails can be driven in it it is thought that the uses is, however, in reinforced concrete barge building in Japan that it is best known This concrete is stated to be about 60 per cent lighter than the ordinary kind, and is said to be absolutely resistant to age by wrer erosion, or serious breakmate cost of such a reinforced concrete is cive with a cargo capacity of 180 t vessels each, as \$5,982 apiece. The current prices of "Koka Seki" in Tokyo are about 1 yen $(\$ 0.50)$ per cubic foot for
blocks, and 33 sen $(\$ 0.17)$ per cubic foot for flakes and sand.
LEGAL NOTICES P A T E N T S

IF YOU HAVE AN INVENTION write fully and freely to Munn \& Co. for advice in regard to the best way of obtaining protection. Please send sketches or a model of your invention and a description of
device, explaining its operation.

All communications are strictly confidential. Our vast practice, extending over a period of seventy years, enables us in many cases to advis
in regard to patentability withou in regard to patentability withou any expense to the client. Our Hand-
Book on Patents is sent free on quest. This explains our methods, terms, etc., in regard to Patents, SCIENTIFIC AMERICAN Contains Patent Ooffice Notes, Decisiont of
interest to inventors-and particulars of re-

MUNN \& CO., SOPIOTTENT Woolworth Building.
Tower Building.
NEW YORK
CHICAGO, ILL. Scientific American Bailding, WASHHNG ON, D. W Annual Subscription Rates Scientific American Publication



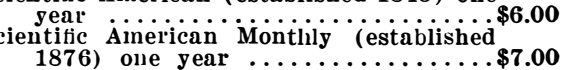
age prepaid in United States and posses-
sions, Mexico, Cuba and Panama. Foreign Postage
Scientific American \$1.50 per year additional.
Scientific American Monthly $72 \mathrm{2c}$ per year additional. Canadian Postage Scientific Americanadian Postage
Scientific American Monthy year additional.
36c per year additional.
comber subscription rates and rates to
forein countries, including Canada, will be

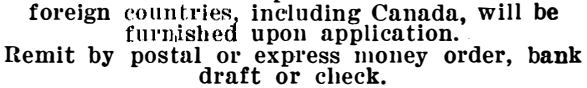

Classified Advertisements Advertising in this column is $\$ 1.00$ a line.
No less than five nor more than 12 lines
accepted Coont seven, words to the line. All
orders must be accompanied by a remittance.

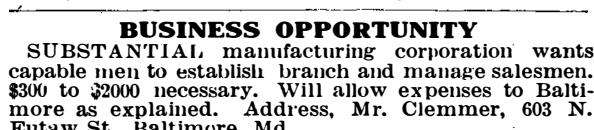
more as explained. Addre
Eutaw St., Baltimure. Md.

\begin{tabular}{l} 
FOR SALE \\
$\begin{array}{l}\text { CANADIAN Patent Rights on ecentric boring chuck } \\
\text { W. F. MYERS COMPANY } \\
\text { for sale. } \\
\text { Bedford, Indiana }\end{array}$ \\
\hline
\end{tabular} PATENT Office DraftsmanTED lary desired. Muml \& Co., 233 Broadway, New York
Gry.

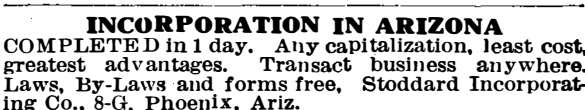
JEWELRY REPAIRING


Property returned im mediately if price not acceptable.
Send Turpish \& Sons, 118 Stapleton, New York City.

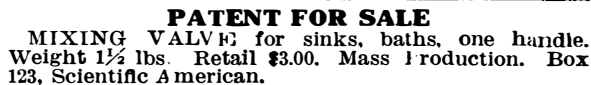

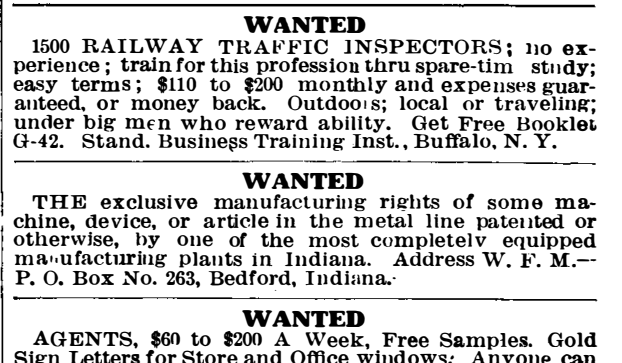



For Spot Cash mail false teeth, old and watches, old gold, silver, platinum, war Bolds or
Stamps-anything valuable. Cash, by return mail
Goods returned in 0 days if you're not satisfled. hio Smelting and Refining Co., 234 Lennox Bldg., Cleveland, 0 .

Printing Cheap

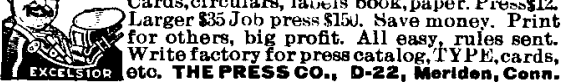

